\title{
EXPRESS LETTER
}

\section{On the change of ${ }^{3} \mathrm{He} /{ }^{4} \mathrm{He}$ ratios in hot spring gases after The Iwate-Miyagi Nairiku Earthquake in 2008}

\author{
KEIKA HORIGUCHI* and JUN-ICHI MATSUdA \\ Department of Earth and Space Science, Graduate School of Science, Osaka University, Toyonaka, Osaka 560-0043, Japan \\ (Received August 14, 2008; Accepted October 9, 2008; Online published November 7, 2008)

\begin{abstract}
The Iwate-Miyagi Nairiku Earthquake in 2008 (M7.2) occurred on June 14th 2008 in the northeastern Japan, Iwate
\end{abstract} \\ Prefecture. We collected water and gas samples in hot springs from seven localities around the epicenter of the earthquake \\ on June 21 st and 22nd, one week after the earthquake, and measured the ${ }^{3} \mathrm{He} /{ }^{4} \mathrm{He}$ ratio and $\mathrm{He}$ and $\mathrm{Ne}$ concentrations of \\ the dissolved gases. We found $10-85 \%$ increases in ${ }^{3} \mathrm{He} /{ }^{4} \mathrm{He}$ ratios in five hot springs, while we found $11-35 \%$ decrease in \\ two others. The positive anomalies were interpreted as upwelling of aqueous fluid containing mantle ${ }^{3} \mathrm{He}$ beneath the \\ earthquake region. It is possible that ascending fluids triggered the earthquake.
}

Keywords: helium isotopes, noble gas, earthquake, epicenter, Japan

\section{INTRODUCTION}

Recent geophysical research in northeastern Japan suggest that aqueous fluids supplied by the subducting slab are transported upward to shallow levels where they may weaken the surrounding crustal rocks, resulting in local compressional/tensional deformation and increasing the local crustal contraction rate (e.g., Hasegawa et al., 2005). Thus ascending fluids of mantle origin may trigger shallow crustal earthquakes by the mechanism of pore-pressure diffusion (i.e., relaxation) (Parotidis et al., 2005). However, the presence of fluids is generally inferred by seismic velocity anomalies and stochastic modeling (Hainzl and Ogata, 2005). It is difficult to directly detect the presence of enhanced upwelling fluid flow using geophysical techniques.

Helium isotopic ratio could be a good tracer to identify the uprising of deep-seated fluids. These fluids often contain measureable traces of mantle-derived helium, particularly in volcanic areas as Japan (e.g., Sano and Wakita, 1985). Mantle helium is characterized by the occurrence of primordial ${ }^{3} \mathrm{He}$ with a typical ${ }^{3} \mathrm{He} /{ }^{4} \mathrm{He}$ ratio of $8 \mathrm{Ra}\left(1 \mathrm{Ra}=1.4 \times 10^{-6}\right.$; $\mathrm{Ra}$ means the ${ }^{3} \mathrm{He} /{ }^{4} \mathrm{He}$ ratio of the atmosphere). This is very different from the low ${ }^{3} \mathrm{He} /$ ${ }^{4} \mathrm{He}$ ratio in the crust $\left(10^{-2}-10^{-1} \mathrm{Ra}\right)$ because of the addition of large amounts of ${ }^{4} \mathrm{He}$ produced via the radioactive decay of Th and $\mathrm{U}$ contained in the crustal rocks.

*Corresponding author (e-mail: keika@ess.sci.osaka-u.ac.jp) Copyright $@ 2008$ by The Geochemical Society of Japan.
In the northeastern Japan, where a typical island arc structure is developed on the subduction zone, there is a clear trend in the ${ }^{3} \mathrm{He} /{ }^{4} \mathrm{He}$ ratio values which is perpendicular to the arc axis; low ${ }^{3} \mathrm{He} /{ }^{4} \mathrm{He}$ ratios in the front arc and high ${ }^{3} \mathrm{He} /{ }^{4} \mathrm{He}$ ratios in the volcanic arc (Sano and Wakita, 1985; Sano and Nakajima, 2008). However, this typical trend across the island arc is not well observed throughout all of northeastern Japan. For example, all the samples in the volcanic arc for $38-39^{\circ} \mathrm{N}$ have values between 2 to $5 \mathrm{Ra}$, but those in the $39-39.5^{\circ} \mathrm{N}$ area have ratios as low as $1 \mathrm{Ra}$; this indicates the presence of crustal material under the arc, which agrees well with the underground structure obtained from seismic velocity data (Horiguchi, 2008). The Iwate-Miyagi Nairiku Earthquake in 2008 occurred in such a low ${ }^{3} \mathrm{He} /{ }^{4} \mathrm{He}$ ratio area, and thus ${ }^{3} \mathrm{He} /{ }^{4} \mathrm{He}$ ratios could be a good tracer to identify the origin of the aqueous fluid.

Here we present some helium isotopic data measured in hot springs from the Iwate Prefecture in a radius of about $40 \mathrm{~km}$ around the epicenter of The Iwate-Miyagi Nairiku Earthquake in 2008 which suggests a primary role of mantle-derived fluids in triggering the earthquake.

\section{Samples and He Measurements}

The Iwate-Miyagi Nairiku Earthquake in 2008 occurred on June 14th 2008 . The epicenter was $39^{\circ} 1.7^{\prime} \mathrm{N}$ $140^{\circ} 52.8^{\prime} \mathrm{E}$ with a magnitude M7.2 and a depth of $8 \mathrm{~km}$ (source: Japan Meteorological Agency). Horiguchi (2008) collected hot spring and gas samples throughout this region in May and July in 2006 and measured He isotopic 


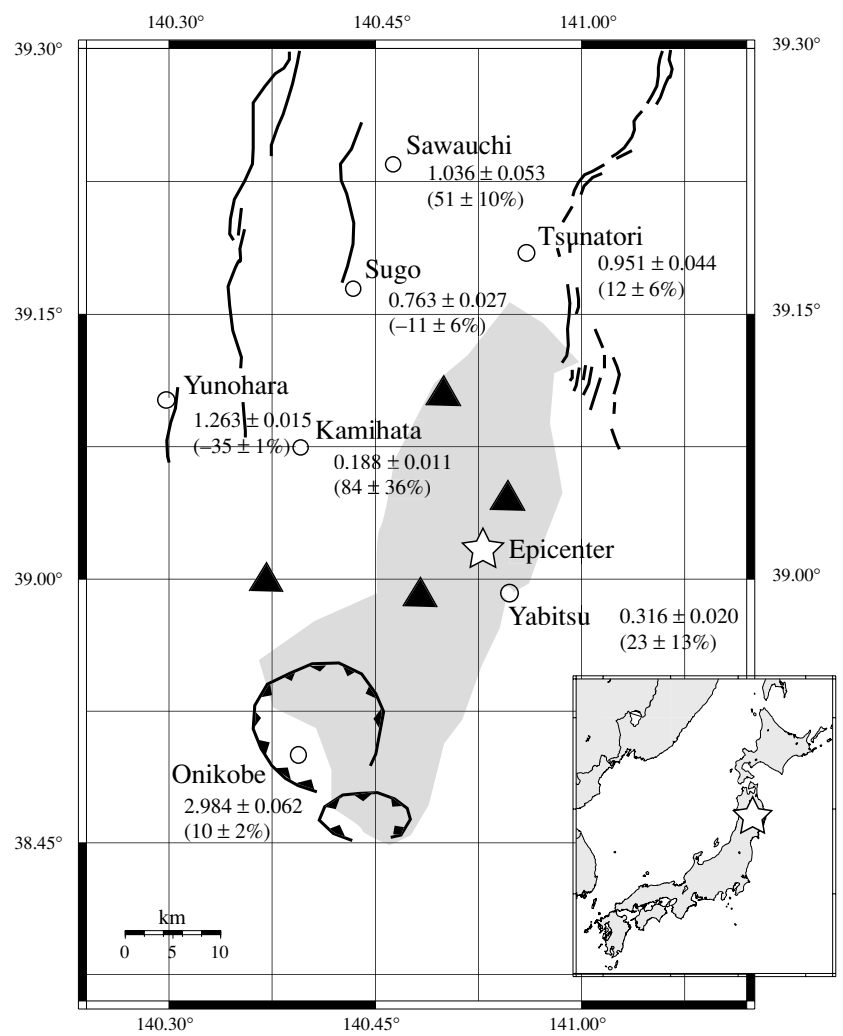

Fig. 1. The sampling locations (open circles) and the epicenter (star mark) of the Iwate-Miyagi Nairiku Earthquake in 2008. The inset shows the epicenter location relative to the entire Japanese island chain. Thick lines show the location of active Quaternary faults. The filled triangles are Quaternary volcanoes, and the line with triangles shows caldera rim (from Maps of Active Faults in Japan). The gray area shows the epicenters of the aftershocks (source: Japan Meteorological Agency). The ${ }^{3} \mathrm{He} /{ }^{4} \mathrm{He}$ ratio (corrected for air component; see text) after the earthquake and the increase rate (in the parenthesis) of the ${ }^{3} \mathrm{Hel}$ ${ }^{4} \mathrm{He}$ ratio relative to that before the earthquake are given.

ratios and $\mathrm{He}$ and $\mathrm{Ne}$ concentrations. For the present study, we collected samples in seven localities around the epicenter on June 21st and 22nd 2008, only a week after the earthquake. The sampling localities are given in Fig. 1. All samples are hot spring water except for Onikobe, where gas samples were collected using a water displacement method and stored in a container with vacuum valves at both ends (e.g., Sano et al., 1986; Matsumoto et al., 2003). Two kinds of glass containers were used; lead glass with a volume of $50 \mathrm{~cm}^{3}$ and Pyrex with a volume of 100 $\mathrm{cm}^{3}$. The gas dissolved in the water samples was extracted by pouring the water into a connecting glass container under vacuum at the laboratory.

The ${ }^{3} \mathrm{He} /{ }^{4} \mathrm{He}$ ratio and the concentrations of $\mathrm{He}$ and Ne were determined using a noble gas mass spectrometer VG5400 installed at Osaka University. All measurements were carried out within two weeks after the sample collection. Helium analyses were calibrated against the HESJ (Helium Standard of Japan; $20.63 \pm 0.10 \mathrm{Ra}$ ) to determine the isotopic discrimination (Matsuda et al., 2002). The ${ }^{3} \mathrm{He} /{ }^{4} \mathrm{He}$ ratios of air were $1.002 \pm 0.056 \mathrm{Ra}$ and 0.989 $\pm 0.053 \mathrm{Ra}$ during the measurement period, confirming that the obtained values were identical with the real air value ( $1 \mathrm{Ra}$ ) within errors. Results are reported in Table 1. For the Onikobe and Kamihata sites we made measurements twice for different glass containers, and the obtained results agree well each other (Table 1). For the samples collected before the earthquake, only the lead glass containers were used and the measurements were carried out at the Ocean Research Institute of The University of Tokyo. The details of the measurements are given in Horiguchi (2008) and those values are also given in Table 1.

\section{RESUlTS AND DISCUSSION}

To avoid the effect of air contamination during the sampling and/or in the sample itself we corrected the obtained ${ }^{3} \mathrm{He} /{ }^{4} \mathrm{He}$ ratio using the ${ }^{4} \mathrm{He} /{ }^{20} \mathrm{Ne}$ ratios (Table 1 ). The ${ }^{3} \mathrm{He} /{ }^{4} \mathrm{He}$ ratio in air is $1 \mathrm{Ra}$ and its ${ }^{4} \mathrm{He} /{ }^{20} \mathrm{Ne}$ ratio is 0.318 . We assumed the ${ }^{4} \mathrm{He} /{ }^{20} \mathrm{Ne}$ ratios of the mantle and the crust to be 5000 (Horiguchi, 2008). We made the following calculation;

$$
\begin{aligned}
\left({ }^{3} \mathrm{He} /{ }^{4} \mathrm{He}\right)_{\mathrm{c}}= & (1 / 5000-1 / 0.318) /\left(1 /\left({ }^{4} \mathrm{He} /{ }^{20} \mathrm{Ne}\right)_{\mathrm{m}}\right) \\
& \times\left(\left({ }^{3} \mathrm{He} /{ }^{4} \mathrm{He}\right)_{\mathrm{m}}-1\right)+1
\end{aligned}
$$

where $\left({ }^{3} \mathrm{He} /{ }^{4} \mathrm{He}\right)_{\mathrm{c}}$ is the corrected ${ }^{3} \mathrm{He} /{ }^{4} \mathrm{He}$ ratio and the subscript " $\mathrm{m}$ " indicates the measured value. The calculated $\left({ }^{3} \mathrm{He} /{ }^{4} \mathrm{He}\right)_{\mathrm{c}}$ should represent only the mixture of the mantle and crustal helium (Table 1).

We plotted $\left({ }^{3} \mathrm{He} /{ }^{4} \mathrm{He}\right)_{\mathrm{c}}$ after the earthquake and the percentage of variation in the ratio in Fig. 1. Among the samples, the sampling locations at Sugo were different, although belonging to the same hot spring area. Thus, it may not be accurate to compare directly the pre- and postearthquake $\left({ }^{3} \mathrm{He} /{ }^{4} \mathrm{He}\right)_{\mathrm{c}}$ for Sugo hot spring.

For Onikobe, Yabitsu, Kamihata and Tsunatori and Sawanouchi samples, we observed an increase in the ${ }^{3} \mathrm{He} /$ ${ }^{4} \mathrm{He}$ ratios ranging from 10 to $85 \%$ (Fig. 1 and Table 1). In contrast, the ratio at Yunohara decreases by $35 \%$. It is noteworthy that Yunohara is a cold spring (temperature lower than $20^{\circ} \mathrm{C}$ ), while all other springs have higher temperatures up to $40^{\circ} \mathrm{C}$. Thus, the origin of the springs may be different only for Yunohara. Yunohara is at the western side and is just on the active fault that is not related the earthquake in this time (Fig. 1). It is very likely that some different mechanism to release radiogenic ${ }^{4} \mathrm{He}$ occurred in this site. The Iwate-Miyagi Nairiku Earthquake in 2008 is supposed to be associated with a reverse fault 
Table $1 .{ }^{3} \mathrm{He} /{ }^{4} \mathrm{He}$ and ${ }^{4} \mathrm{He} /{ }^{20} \mathrm{Ne}$ ratios and the increase rate of the ${ }^{3} \mathrm{He} /{ }^{4} \mathrm{He}$ ratio after the earthquake

\begin{tabular}{lccccc}
\hline Sample location ${ }^{* 1}$ & $\begin{array}{c}\left({ }^{3} \mathrm{He} /{ }^{4} \mathrm{He}\right)_{\mathrm{m}}{ }^{* 2} \\
(\mathrm{Ra})\end{array}$ & $\begin{array}{c}\left({ }^{4} \mathrm{He} /{ }^{20} \mathrm{Ne}\right) \\
\left(\begin{array}{l}\left.{ }^{3} \mathrm{He} /{ }^{4} \mathrm{He}\right)_{\mathrm{c}}{ }^{* 3} \\
(\mathrm{Ra})\end{array}\right.\end{array}$ & $\begin{array}{c}\left({ }^{3} \mathrm{He} /{ }^{4} \mathrm{He}\right)_{\text {cbefore }} \\
(\mathrm{Ra})\end{array}$ & $\begin{array}{c}{ }^{* 4} \\
(\%)\end{array}$ \\
\hline Sawauchi & $1.018 \pm 0.026$ & 0.637 & $1.036 \pm 0.053$ & $0.686 \pm 0.031$ & $51 \pm 10$ \\
Tsunatori & $0.951 \pm 0.044$ & 70.4 & $0.951 \pm 0.044$ & $0.848 \pm 0.020$ & $12 \pm 6$ \\
Sugo & $0.832 \pm 0.019$ & 1.09 & $0.763 \pm 0.027$ & $0.854 \pm 0.049$ & $-11 \pm 6$ \\
Yunohara & $1.258 \pm 0.014$ & 16.5 & $1.263 \pm 0.015$ & $1.940 \pm 0.031$ & $-35 \pm 1$ \\
Kamihata & $0.273 \pm 0.012$ & 2.98 & $0.186 \pm 0.013$ & $0.102 \pm 0.027$ & $82 \pm 50$ \\
& $0.285 \pm 0.015$ & 2.72 & $0.190 \pm 0.017$ & $0.102 \pm 0.027$ & $87 \pm 52(84 \pm 36)$ \\
Yabitsu & $0.367 \pm 0.019$ & 4.26 & $0.316 \pm 0.020$ & $0.258 \pm 0.022$ & $23 \pm 13$ \\
Onikobe & $2.320 \pm 0.061$ & 0.872 & $3.077 \pm 0.096$ & $2.722 \pm 0.014$ & $13 \pm 4$ \\
& $1.983 \pm 0.041$ & 0.663 & $2.890 \pm 0.079$ & $2.722 \pm 0.014$ & $6 \pm 3(10 \pm 2)$ \\
Air & & 0.318 & 1 & & \\
\hline
\end{tabular}

\footnotetext{
${ }^{*}$ The second values of Kamihata and Onikobe are for the sample in the lead-glass container. All others are for the sample in the Pyrex glass container.

${ }^{*}$ The measured ${ }^{3} \mathrm{He} /{ }^{4} \mathrm{He}$ ratio.

${ }^{*}{ }^{3}$ Corrected ${ }^{3} \mathrm{He} /{ }^{4} \mathrm{He}$ ratio for the air component using ${ }^{4} \mathrm{He} /{ }^{20} \mathrm{Ne}$ ratio (see text).

${ }^{*}{ }^{4}$ Corrected ${ }^{3} \mathrm{He}{ }^{4} \mathrm{He}$ ratio before the earthquake (from Horiguchi, 2008).

${ }^{*}$ The value in the parenthesis is the mean value of two measurements.
}

movement due to E-W compression. The surface slip direction at the earthquake was perpendicular to the axis (NNE-SSW) of the epicenter region of the aftershocks (Fig. 1). One may think that the increase/decrease of the ${ }^{3} \mathrm{He} /{ }^{4} \mathrm{He}$ ratio is related with compressional/extensional feature of the region. However, all the sampling locations including Yunohara are supposed to be in compression field, and the decrease of the ${ }^{3} \mathrm{He} /{ }^{4} \mathrm{He}$ ratio in Yunohara is not related with this feature. The ${ }^{4} \mathrm{He} /{ }^{20} \mathrm{Ne}$ ratio of Yunohara is as high as 16.5 although it is not so high as 70.4 of Tsunatori that is at the north side of the epicenters of the aftershocks (Fig. 1). We have not made an accurate quantitative analysis of the ${ }^{4} \mathrm{He}$ concentration of Yunohara, but it is estimated to be higher than that of other samples by about an order of magnitude, judging from the peak intensity at the measurement. Thus, it is likely that some radiogenic ${ }^{4} \mathrm{He}$ from the crustal rocks was supplied in this sample.

Anyway, our results suggest that the ${ }^{3} \mathrm{He} /{ }^{4} \mathrm{He}$ ratios increased by $10-85 \%$ in most of the hot springs in this region after the earthquake (Fig. 1 and Table 1). We do not think this is due to the normal variance. The sampling seasons are almost the same before and after the earthquake, so we can not expect large isotopic variations caused by changes in the hydrologic cycle. If the variation is due to the normal variance, the change (increase or decrease) of the ${ }^{3} \mathrm{He} /{ }^{4} \mathrm{He}$ ratios should be at random. The probability that the $\mathrm{He}$ ratio in five hot spring increases is $1 / 32$, that in five of six hot springs is $6 / 64$ (in case including Yunohara).

Previous studies on the change of the ${ }^{3} \mathrm{He} /{ }^{4} \mathrm{He}$ ratios before and after an earthquake show that they can both increases and decreases after an earthquake. For the 1995 South Hyogo Prefecture Earthquake (M7.2), the ${ }^{3} \mathrm{He} /{ }^{4} \mathrm{He}$ ratios of ground water samples decreased by about 20 $40 \%$, which was interpreted as being due to the release of radiogenic ${ }^{4} \mathrm{He}$ as a result of micro-fracturing of rocks (Sano et al., 1998). The basement in the South Hyogo Prefecture is granitic, possibly enhancing the radiogenic production of ${ }^{4} \mathrm{He}$ from the decay of $\mathrm{U}$ and $\mathrm{Th}$. Igarashi et al. (1995) also reported the increase of radon in groundwater before the 1995 South Hyogo Prefecture Earthquake, which is also due to the formation of micro-cracks in the aquifer system.

In contrast, after the 1984 Western Nagano Earthquake (M6.8) the ${ }^{3} \mathrm{He} /{ }^{4} \mathrm{He}$ ratios of four bubbling gas increased at hot springs located less than $10 \mathrm{~km}$ from the newly formed fault (comparison between 1981 and 1984 after the earthquake), indicating that the earthquake was triggered by an upward migration of the ${ }^{3} \mathrm{He}$-containg fluids associated with magma intrusion beneath the source region (Sano et al., 1986). The three samples of which ${ }^{3} \mathrm{He} /$ ${ }^{4} \mathrm{He}$ ratios decreased after the earthquake were located more than $10 \mathrm{~km}$ from the fault although one sample shows the increase of the ratio in this area. A similar increase of ${ }^{3} \mathrm{He} /{ }^{4} \mathrm{He}$ ratios was also reported after The Niigataken Chuetsu-oki Earthquake in 2007 (Horiguchi, 2008) where the ${ }^{3} \mathrm{He} /{ }^{4} \mathrm{He}$ ratios of gas well increased in all six sampling sites, indicating the intrusion of magmatic fluid to the crustal shallow part.

Our results show ${ }^{3} \mathrm{He} /{ }^{4} \mathrm{He}$ variations in a similar fashion to those observed during the 1984 Western Nagano Earthquake (Sano et al., 1986) and The Niigataken Chuetsu-oki Earthquake in 2007 (Horiguchi, 2008). For 
comparison, we can speculate that upwelling of the deepseated fluids containing primordial ${ }^{3} \mathrm{He}$ excess produced the observed $\mathrm{He}$ isotopic variations in the hot springs of Iwate Prefecture.

The injection of large amount of deep-seated fluids could have triggered the earthquake. The Emergency Observation Group (Tohoku University) for The IwateMiyagi Nairiku Earthquake in 2008 gave a preliminary short report of their seismological research for the Coordinating Committee for Earthquake Prediction (CCEP material \#178) on the internet website (http:// www.aob.geophys.tohoku.ac.jp/download/yochiren/siryo/ 178_1.pdf) on August 18th. A vertical cross-section of Swave perturbations along the earthquake region (figure $7 \mathrm{e}$ of the report) showed the occurrence of a low-velocity layer corresponding to the upwelling channel of aqueous fluid under the main shock epicenter region (Okada et al., 2007, 2008). Thus, our geochemical observations related to the upwelling of mantle-derived fluids seem to be much compatible with the seismological data.

Acknowledgments-We would like to thank Dr. Matsumoto for his kind help to make the location map. Thank are also to anonymous reviewers for their comments, and also to Prof. Pinti for his careful reading and suggestions for improving the manuscript. We also thank Dr. Okada for the seismological information and individual owners of hot springs for their cooperation at the sampling.

\section{REFERENCES}

Hainzl, S. and Ogata, Y. (2005) Detecting fluid signals in seismicity data through statistical earthquake modeling. $J$. Geophys. Res. 110, B05S07, doi:10.1029/2004JB003247.

Hasegawa, A., Nakajima, J., Umino, N. and Miura, S. (2005) Deep structure of the northeastern Japan arc and its implications for crustal deformation and shallow seismic activity. Tectonophysics 403, 59-75.

Horiguchi, K. (2008) Spacial distribution of helium isotopic ratios in the northeastern Japan. Ms. Thesis, Tohoku University (in Japanese).
Igarashi, G., Saeki, S., Takahata, N., Sumikawa, K., Tasaka, S., Sasaki, Y., Takahashi, M. and Sano, Y. (1995) Groundwater radon anomaly before the Kobe earthquake in Japan. Science 269, 60-61.

Matsuda, J., Matsumoto, T., Sumino, H., Nagao, K., Yamamoto, J., Miura, Y., Kaneoka, I., Takahata, N. and Sano, Y. (2002) The ${ }^{3} \mathrm{He} /{ }^{4} \mathrm{He}$ ratio of the new internal He Standard of Japan (HESJ). Geochem. J. 36, 191-195.

Matsumoto, T., Kawabata, T., Matsuda, J., Yamamoto, K. and Mimura, K. (2003) ${ }^{3} \mathrm{He} /{ }^{4} \mathrm{He}$ ratios in well gases in Kinki district, SW Japan: surface appearance of slab-derived fluids in a non-volcanic area in Kii Peninsula. Earth Planet. Sci. Lett. 216, 221-230.

Okada, T., Nii, K., Hasegawa, H., Zhang, H. and Thurber, C. (2007) Deep structure of the strain concentration Zone in northern Miyagi Prefecture, NE Japan. Eos Trans. AGU, 88, Fall Meet. Suppl., Abstract S33D-04.

Okada, T., Umino, N., Hasegawa, A., Group for the aftershock observations of The Iwate-Miyagi Nairiku Earthquake in 2008 (2008) Imaging inhomogeneous seismic velocity structure in and around the fault plane of the 2008 Iwate-Miyagi, Japan, Nairiku Earthquake (M7.2) - spatial variation in depth of seismic-aseismic transition and possible high-T/ overpressurized fluid distribution. Eos Trans. AGU, 89, Fall Meet. Suppl. (submitted).

Parotidis, M., Rothert, E. and Shapiro, S. A. (2005) Evidence for triggering of the Vogtland swarms 2000 by pore pressure diffusion. J. Geophys. Res. 110, B05S10, doi:10.1029/ 2004JB003267.

Sano, Y. and Nakajima, J. (2008) Geographical distribution of ${ }^{3} \mathrm{He} /{ }^{4} \mathrm{He}$ ratios and seismic tomography in Japan. Geochem. J. 42, 51-60.

Sano, Y. and Wakita, H. (1985) Geographical distribution of ${ }^{3} \mathrm{He} /{ }^{4} \mathrm{He}$ ratios in Japan: Implications for arc tectonics and incipient magmatism. J. Geophys. Res. 90, 8729-8741.

Sano, Y., Nakamura, Y. and Wakita, H. (1986) ${ }^{3} \mathrm{He} /{ }^{4} \mathrm{He}$ ratio anomalies associated with the 1984 Western Nagano Earthquake: Possibly induced by a diapiric Magma. J. Geophys. Res. 91, 12291-12295.

Sano, Y., Takahara, N., Igarashi, G., Koizumi, N. and Sturchio, N. C. (1998) Helium degassing related to the Kobe earthquake. Chem. Geol. 150, 171-179. 